\title{
Involuntary Movements in Patients Taking Oral Contraceptives
}

\author{
P. D. LEWIS,*M.B., B.SC., M.R.C.P. ; M. J. G. HARRISON,* D.M., M.R.C.P.
}

British Medical fournal, 1969, 4, 404-405

\begin{abstract}
Summary : Involuntary movements developed in five women taking oral contraceptives. In one, the sudden onset of a unilateral disturbance suggested a cerebral thrombosis; this case is considered to be a further example of the increased risk of cerebrovascular disease associated with oral contraception. The four other patients suffered a relapse of Sydenham's chorea between one and four months after starting an oral contraceptive regimen. Possibly an underlying vascular mechanism was responsible for these relapses.
\end{abstract}

\section{Introduction}

In recent years a number of neurological conditions have been found to be associated with taking oral contraceptives of the conventional oestrogen-progesterone type. Headache is one of the commonest side-effects encountered by women receiving such medication (Mears and Grant, 1962; British Medical fournal, 1968), and migraine may be aggravated or may arise de novo (Whitty et al., 1966 ; Phillips, 1968). Cerebral infarction, a rare occurrence in migraine (Guest and Woolf, 1964), is said to be more common in migrainous subjects on oral contraceptives (Altshuler et al., 1968). Depression and psychoses have also been reported (Daly et al., 1967).

In 1964 Zilkha described two cases of cerebrovascular accidents in young women on " the pill," and further cases soon followed (Illis et al., 1965; Bickerstaff and Holmes, 1967). The statistical significance of an association between the oral contraceptive and cerebrovascular lesions has now been established (Vessey and Doll, 1968, 1969 ; Inman and Vessey, 1968), and over 100 cases have now been recorded (Bergeron and Wood, 1969). Angiographic studies have shown that the pathological lesion is usually an arterial thrombosis.

In 1966 Fernando described a case of chorea complicating the use of oral contraceptives. We have recently seen five women who developed involuntary movements while receiving oral contraceptives, and this paper describes their case histories and discusses the practical and theoretical implications.

\section{Case 1}

Six days after she began to take Gynovlar 21 (norethisterone) the patient, who was 40 years old, noticed difficulty in keeping her left shoe on her foot while shopping. Within 20 minutes she began to feel unwell and experienced severe stiffness and weakness of the left arm and leg, with numbness of the left side of the face. When she was examined an hour later her weakness had almost disappeared.

A few hours afterwards she became troubled by gross involuntary pumping movements of the left arm, which subsequently made eating and washing difficult and kept her awake. Twitching of the left side of the trunk was also noticed. These symptoms settled over the next three days; but three weeks later-by which time she had stopped taking her oral contraceptive-mild pyramidal signs were still demonstrable in the left limbs and choreiform movements were still present in the left hand. The patient had a normal blood pressure, and there was no clinical evidence of heart disease. Her haemoglobin, white cell count, sedimentation rate, blood sero-

* Senior Resident House-physician, the National Hospital for Nervous Diseases, Queen Square, London W.C.1. logy, serum cholesterol, urine, chest and skull $x$-ray pictures, E.C.G., and brain scan were all normal.

\section{Case 2}

A 27-year-old housewife presented with predominantly right-sided choreiform movements of 12 months' duration. She gave a history of "rheumatism of the hip" which required three weeks of bedrest at the age of 13, and of Sydenham's chorea at the age of 16 . The latter illness lasted about five months and affected all four limbs. No evidence of cardiac involvement was found. The patient's mother had had three attacks of rheumatic fever, and her sister had had chorea gravidarum.

Uneventful pregnancies occurred at the ages of 24 and 26, and in March 1967 the patient started to take Ovulen. After four weeks involuntary movements were noted in the right arm and leg, and these persisted unchanged up to the time of her outpatient attendance. Examination revealed typical and moderately severe chorea of the righi arm and leg, and similar though milder movements in the left foot. The cardiovascular system was normal, as were her haemoglobin, white cell count, sedimentation rate, chest $x$-ray film, and E.C.G.

As it was believed that the movements were attributable to the drug, the patient was fitted with an intrauterine contraceptive device and in October 1968 Ovulen was withdrawn. For eight weeks no significant improvement was observed, but early in December the movements began to diminish in intensity, and by Christmas they had gone.

\section{Case 3}

This patient developed rheumatic chorea at the age of 16 . She responded to treatment with bed rest and sedation in hospital, but six months later her involuntary movements returned and she was admitted to the National Hospital, Queen Square. There she was found to have severe widespread choreiform movements and mild valvular aortic stenosis. Her sedimentation rate and antistreptoiysin titre were normal, and she was successfully treated with bed rest, sedation, and penicillin by mouth. By mid-1963, nine months later, all choreiform movements had disappeared, and she remained well over the next five years.

Prophylactic penicillin was stopped in 1966. In 1967 she became pregnant. During the pregnancy, which was terminated therapeutically at eight weeks, no recurrence of her chorea was noted.

In September 1968 she began taking an oral contraceptive (Feminor 21) for the first time. Within one month she noticed the gradual appearance of involuntary fidgety movements, particularly of the right arm and leg. She recognized the return of her chorea.

She was seen at the National Hospital in November 1968, when widespread choreiform movements of all limbs were noted. There was no evidence of active carditis and her antistreptolysin-O titre and sedimentation rate were normal. In hospital she was again treated with sedation and penicillin. During the ensuing months, having been advised not to use oral contraceptives, she showed a steady improvement, with a reduction in the frequency and severity of her movements.

\section{Case 4}

An 18-year-old hairdresser gave a history of rheumatic fever with Sydenham's chorea and cardiac involvement at the age of 10. The abnormal movements had principally affected the right arm and leg, and had lasted about two months. She was treated with sulphonamides for a total of six years. 
Three months after starting on Minovlar (norethisterone) she noticed difficulty in speaking on account of a feeling that her tongue was too big for her mouth. At the same time she complained of clumsiness of the right hand and of twitching of the right side of the mouth, right shoulder, arm, and leg. She felt lethargic and depressed.

On examination she was afebrile. There was evidence of trivial mitral incompetence, but none of acute rheumatism, active carditis, or bacterial endocarditis. She had obvious choreiform movements of face, tongue, and limbs, the right side being more affected than the left. She was unable to maintain a protruded tongue and showed hypotonic posturing of the outstretched hands. A beta-haemolytic streptococcus was grown from a throat swab, but the antistreptolysin-O titre was not raised and the sedimentation rate was normal. Her movements subsided with rest and thiopropazate (Dartalan). She has stopped taking her oral contraceptive and has restarted on sulphonamides.

\section{Case 5}

A 27-year-old schoolteacher had had Sydenham's chorea at the age of 11. At the beginning of 1969 she began taking an oral contraceptive and after four months noticed the appearance of twitching movements of the left side of the body. She also found some difficulty in speaking clearly. When she was examined in the outpatient clinic involuntary choreiform movements were seen in the left arm. After two months' rest at home the movements had largely disappeared.

\section{Discussion}

In the first patient, involuntary movements appeared in limbs affected by the sudden onset of weakness. The focal nature of the disturbance (hemichorea), its sudden onset, and its gradual resolution are features of a vascular lesion, which is the common cause of unilateral involuntary movements, at least in the elderly and hypertensive (Martin, 1927).

Women normally show a degree of immunity to vascular disease (Kannel et al., 1961), but thrombosis does occur more readily during the administration of oral contraceptives. Venous thrombosis is also more common during the suppression of lactation by oestrogens (Daniel et al., 1967), and the treatment of prostatic carcinoma with stilboestrol leads to an increased mortality from ischaemic heart disease and stroke (Bailar, 1967). The oestrogenic component of the contraceptive therefore seems likely to be responsible, a view supported by laboratory studies (Bolton et al., 1968 ; Elkeles et al., 1968), which show that changes in blood platelet behaviour may develop that closely mimic those seen in patients with arterial disease. These changes are due to synthetic oestrogens, and are thought to be due to altered low-density lipoproteins in the plasma (Aurell et al., 1966 ; Bolton et al., 1968). Some blood-clotting factors are also raised in women on the pill (Poller et al., 1968). Although cerebral arterial thrombosis occurs in association with pregnancy and the puerperium (Cross et al., 1968) the risk does not seem to be as high as with the smaller levels of oestrogen involved in taking oral contraceptives. Blood changes may be detected within four days (Bolton et al., 1968), and it is of interest that Case 1 of the present series suffered a cerebrovascular accident after only six days of medication.

In the last four cases involuntary movements developed in women with a past history of Sydenham's chorea who had recently started taking oral contraceptives. The situation appears to be similar to that occurring in chorea gravidarum
(Lewis and Parsons, 1966). The movements of chorea gravidarum are identical with those of Sydenham's chorea, and usually develop in the first half of a pregnancy in a woman with a past history of rheumatic fever or chorea and often with clinical evidence of chronic rheumatic heart disease. Chorea gravidarum is generally accepted to be a form of rheumatic chorea to which patients are predisposed by pregnancy. The pseudo-pregnancy of the pill might be thought to offer a similar predisposition, despite the difference in the hormonal and lipid changes (Aurell et al., 1968).

The pathological findings in cases of rheumatic chorea are variable and diffuse (Blackwood et al., 1963). Early theories that chorea may be due to cerebral embolization were discredited by Greenfield and Wolfsohn in 1922 . Widespread vascular changes, however, were found in some necropsy specimens, and the recurrence with polycythaemia (Gautier-Smith and Prankerd, 1967) is best explained by a diffuse vascular change. It remains possible, therefore, that a vascular mechanism underlies the relapses of rheumatic chorea seen in our patients who were taking oral contraceptives.

We wish to thank Dr. M. Kremer, Dr. R. Henson, Dr. N. Blau, and Dr. P. Gautier-Smith for permission to study patients admitted under their care.

\section{REFERENCES}

Altshuler, J. H., McLaughlin, R. A., and Neubuerger, K. T. (1968). Archives of Neurology, 19, 264.

Aurell, M., Cramér, K., and Rybo, G. (1966). Lancet, 1, 291.

Bailar, J. C. (1967). Lancet, 2, 560.

Bergeron, R. T., and Wood, E. H. (1969). Radiology, 92, 231.

Bickerstaff, E. R., and Holmes, J. M. (1967). British Medical fournal, $1,726$.

Blackwood, W., McMenemey, W. H., Meyer, A., Norman, R. M., and Russell, D. S. (editors) (1963). Greenfield's Neuropathology, 2nd ed. London, Arnold.

Bolton, C. H., Hampton, J. R., and Mitchell, J. R. A. (1968). Lancet, 1, 1336.

British Medical fournal, 1968, 3, 388.

Cross, J. N., Castro, P. O., and Jennett, W. B. (1968). British Medical fournal, 3, 214 .

Daly, R. J., Kane, F. J., and Ewing, J. A. (1967). Lancet, 2, 444.

Danicl, D. G., Campbell, H., and Turnbull, A. C. (1967). Lancet, 2, 287.

Elkeles, R. S., Hampton, J. R., and Mitchell, J. R. A. (1968). Lancet, 2, 315.

Fernando, S. J. M. (1966). Practitioner, 197, 210.

Gautier-Smith, P. C., and Prankerd, T. A. J. (1967). Acta Neurologica Scandinavica, 43, 357.

Greenfield, J. G., and Wolfsohn, J. M. (1922). Lancet, 2, 603.

Guest, I. A., and Woolf, A. L. (1964). British Medical fournal, 1, 225.

Illis, L., Kocen, R. S., McDonald, W. I., and Mondkar, V. P. (1965). British Medical fournal, 2, 1164.

Inman, W. H. W., and Vessey, M. P. (1968). British Medical fournal, 2, 193.

Kannel, W. B., Dawber, T. R., Kagan, A., Revotskie, N., and Stokes, J. (1961). Annals of Internal Medicine, 55, 33.

Lewis, B. V., and Parsons, M. (1966). Lancet, 1, 284.

Martin, J. P. (1927). Brain, 50, 637.

Mears, E., and Grant, E. C. G. (1962). British Medical fournal 2, 75. Phillips, B. M. (1968). British Medical Gournal, 2, 99.

Poller, L., Tabiowo, A., and Thomson, J. M. (1968). British Medical fournal, 3, 218. .

Vessey, M. P., and Doll, R. (1968). British Medical fournal, 1, 199.

Vessey, M. P., and Doll, R. (1969). British Medical fournal, 2, 651.

Whitty, C. W. M., Hockaday, J. M., and Whitty, M. M. (1966). Lancet, $1,856$.

Zilkha, K. J. (1964). British Medical fournal, 2, 1132. 